\title{
Requested meals versus scheduled meals
}

\section{Mario Ciampolini}

Preventive Gastroenterology Unit, Department of Paediatrics, Università di Firenze, Florence, Italy

\section{Video abstract}

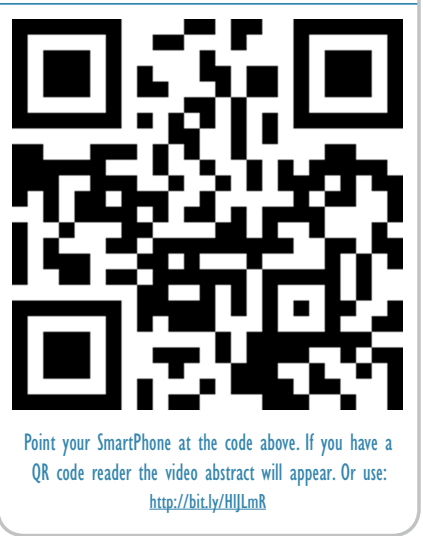

Correspondence: Mario Ciampolini Onlus Nutrizione e Prevenzione, Via Vigna Nuova 8, Firenze,

50132 Florence, Italy

Tel +3905521 5744

Email mlciampolini@fastwebnet.it
This article was published in the following Dove Press journal:

International Journal of General Medicine

12 April 2012

Number of times this article has been viewed

Background: Scheduled meals are considered to be equivalent to those requested by the infant (null hypothesis). In adults, we have found high blood glucose before scheduled meals and low blood glucose after recognition of validated initial hunger. Low preprandial blood glucose is associated with a decrease in energy intake and body weight both in adults who are overtly overweight and in those who are of normal weight with insulin resistance (hidden overweight). In this study, we investigated the validity of the null hypothesis between scheduled and requested meals in 2-year-old infants with chronic nonspecific diarrhea.

Methods: We trained a "recognizing request" meal pattern in 70 mother-infant pairs. The trained meal pattern consisted of administering food after a first request that we validated by blood glucose measurement in the hospital laboratory. Using a 7-day food diary, mothers reported preprandial blood glucose measurements for their infants three times a day. We assessed mean preprandial blood glucose, daily energy intake, days with diarrhea, blood parameters, and anthropometry before training and 4 months after training, and compared the results with measurements in 73 randomly selected untrained controls.

Results: In the trained group, there was a decrease in mean blood glucose from $86.9 \pm 9.4 \mathrm{mg} / \mathrm{dL}$ to $76.4 \pm 6.7 \mathrm{mg} / \mathrm{dL}(P<0.0001)$, as well as a decrease in energy intake and days with diarrhea in comparison with control infants who maintained scheduled meals. Only two of 21 infants who had a mean blood glucose lower than $81.2 \mathrm{mg} / \mathrm{dL}$ at recruitment showed a statistically significant decrease in mean blood glucose, whereas 36 of 49 infants above this cutoff level showed a statistically significant decrease after training (Chi-square test, $P<0.0001)$.

Conclusion: Requested meals are associated with low preprandial blood glucose, significantly lower energy intake, and recovery from diarrhea, whereas scheduled meals are associated with high blood glucose, higher energy intake, and persistence of diarrhea. The disparities in blood glucose levels and energy intake disprove the null hypothesis, suggesting the need for a change from scheduled to requested meals early on in food administration, ie, during the neonatal period.

Keywords: meals, energy, homeostasis, blood glucose, overweight, chronic diarrhea

\section{Introduction}

During the 1960s, the Gastroenterology Unit at the University of Florence became responsible for the treatment of infants with malabsorption and/or malnutrition. At that time we decreased or suspended administration of food, stopped the diarrhea, and then progressively increased administration of food, after which the infants grew well but tended to relapse again. To prevent further relapses, we decided to delay meals as long as possible without causing hunger pains. ${ }^{1}$ As soon as the infants asked for food or manifested discomfort, we administered vegetables and other food. 
This training procedure was termed "recognizing initial request", and stopped relapses, achieved slow but steady growth in the first 2 months of recovery, and improved growth in the subsequent months in comparison with randomly selected malnourished control infants. ${ }^{1,2}$ This intervention was also successful in infants with diarrhea, who showed biophysical and biochemical parameters, including energy intake and fecal emission, within normal ranges. ${ }^{2,3}$ Physicians and mothers in Florence have followed the 1985 Food and Agriculture Organization recommendations of $105 \mathrm{kcal} / \mathrm{kg} /$ day in the second year of life, and 15 Florentine infants were reported to have an energy intake of $98.2 \pm 19.0 \mathrm{kcal} / \mathrm{kg} /$ day by 7 -day diary. ${ }^{2,3}$ At recruitment for the present study, the energy intake of infants with persistent diarrhea was $92.2 \pm 16.5 \mathrm{kcal} / \mathrm{kg} /$ day in controls and $91.0 \pm 22.1 \mathrm{kcal} / \mathrm{kg} /$ day in intervention infants. These figures are comparable with those of healthy infants.

Commonsense and prevailing scientific opinion attributed development of diarrhea and spontaneous recovery to psychological mechanisms. ${ }^{4-6}$ Either scheduled or requested meals were considered to be equivalent, ie, the null hypothesis. In the mothers' reports, the infants ate more food after request. Mothers compiled 7-day food intake diaries, with preprandial blood glucose measurements showing that the recognition of similar manifestations of request (hunger) corresponded to identical metabolic conditions. They validated the initial request by estimating blood glucose before measurement in the hospital laboratory. Further, the diaries informed investigators regarding prevention of slightly depressed blood glucose $(\leq 60 \mathrm{mg} / \mathrm{dL})$ and changes in intake. Transient and rare slightly depressed blood glucose levels emerged in the first days (61/1347 meals requested by trained infants). Mean blood glucose decreased by $15 \%$ on intervention, leaving sufficient energy for growth and activity. ${ }^{2,3}$

Healthy people on a mixed diet oxidize blood glucose before other nutrients. ${ }^{7-12}$ Abundance of other nutrients spares blood glucose, but does not stop its decline because reserves are exhaustible. ${ }^{7-9}$ We measured blood glucose at its lowest level during the day (before meals) to evaluate provision of total energy to body tissues by meals during the day. We compared meal patterns by the same metabolic parameter to determine the achieved decline in blood glucose. A 7-day home diary with 21 measurements before meals indicated that mean blood glucose remained stable for months in 31 untrained adults. ${ }^{13}$ Mean preprandial blood glucose reflects energy intake habits. ${ }^{13}$ Higher mean blood glucose was $>81.8 \mathrm{mg} / \mathrm{dL}$, and was associated with insulin resistance and a high energy intake,
$\mathrm{HbA}_{1 \mathrm{c}}$, and body weight, as well as few signs of metabolic syndrome in overtly overweight (body mass index $>25$ ) adults and in those normal weight adults who were insulin-resistant (hidden overweight). ${ }^{13}$ Insulin resistance is associated with compromised immunity, ie, a subclinical inflammation or proinflammatory state, ${ }^{14-19}$ implying immune, malignant, and vascular risks, although the individual may be seemingly healthy for years, with few and intermittent subjective complaints. ${ }^{20,21}$ Contrasting high mean blood glucose as well as overt and hidden overweight requires long-term strategies to prevent relapse. ${ }^{22,23}$ Factors responsible included sweetened beverages, low intake of vegetables and fruits, limited physical activity, and use of alcohol. Scheduled meal consumption may include all these detrimental factors, leading to persistent energy accumulation.

Infant energy intake as recorded in mothers' diaries decreased alarmingly by one third after cessation of scheduled meals. ${ }^{1-3}$ Infants have shown similar differences in energy intake when switched from breast milk to formula feeding. ${ }^{24}$ Rearing children on scheduled meals may promote uncontrolled energy intake, overweight, and insulin resistance. The null hypothesis between either scheduled or requested meals is sustained by common wisdom but might be false. Here we report a randomized, controlled investigation of infant energy intake, mean blood glucose levels, days with diarrhea, and the results of relevant blood tests to show either identity or disparity that affirms or contradicts the null hypothesis in the second year of life.

\section{Materials and methods Participants}

The mother-child pairs used in this study were reported in previous papers. ${ }^{2,3}$ Briefly, the Pediatric Gastroenterology Unit at the University of Florence recruited 143 motherinfant pairs for investigation from 1996 to 2000. The infants were aged 7-36 months (Table 1) and had symptoms of a functional bowel disorder (chronic nonspecific diarrhea), ${ }^{2,3}$ but were otherwise clinically healthy. We investigated for food allergy using the paper radioimmunosorbent test and by measurement of total IgE. We screened the feces of all infants for parasites and viral or bacterial pathogens. ${ }^{1-3}$ Those who were positive were excluded. C-reactive protein was normal. The local hospital ethics committee approved the investigation in compliance with the Declaration of Helsinki. Informed consent was obtained from parents for all the infants. At recruitment, a list assigned the infants randomly (using Armitage odd and even numbers) to either the training group or the control group. 
Table I Group composition and effects of training on anthropometry in control and trained groups

\begin{tabular}{|c|c|c|c|c|}
\hline & Control & & Trained & \\
\hline Subjects $(n)$ and gender & $36 F+37 M$ & & $27 F+43 M$ & \\
\hline Parents' schooling (years)' & $9.1 \pm 3.6$ & & $9.7 \pm 3.0$ & \\
\hline \multirow[t]{2}{*}{ Age (months)' } & $16.7 \pm 6.3$ & & $18.0 \pm 7.4$ & \\
\hline & Recruitment & After 5 months & Recruitment & After 5 months \\
\hline Weight (kg) & $10.5 \pm 1.7$ & $11.0 \pm 1.8^{\mathrm{b} * * *}$ & $10.4 \pm 2.2$ & $11.2 \pm 2.2^{\mathrm{b} * * *}$ \\
\hline Height (cm) & $78.5 \pm 6.8$ & $83.2 \pm 6.2^{\mathrm{b} * *}$ & $80.5 \pm 88.0$ & $84.1 \pm 7.2^{\mathrm{b} * * *}$ \\
\hline Arm skin-fold thickness (mm) & $6.7 \pm 1.5$ & $7.1 \pm 1.3^{\mathrm{b} * * * *}$ & $7.1 \pm 1.5$ & $7.1 \pm 1.6$ \\
\hline Leg skin-fold thickness (mm) & $10.5 \pm 3.0$ & $11.4 \pm 3.4^{6 * *}$ & $11.3 \pm 3.0$ & $11.3 \pm 2.9$ \\
\hline
\end{tabular}

Notes: Values are expressed as the mean \pm standard deviation. 'Values at the beginning of the study. $* P<0.05 ; * * P<0.0$ I; $* * * P<0.00 \mathrm{I}$, Student's $t$-test, statistically significant pre/post difference versus a control group or versus bame group at recruitment.

\section{Training}

Following a brief period of recovery from diarrhea, the trained group exercised regularly under supervision for 7 weeks, and maintained the new strategies of food consumption and energy expenditure for a further 3 months without any assistance. Training started with meal suspension until arousal of "request for food", ${ }^{1-3}$ ie, unexplained disagreeable mood, fussiness, walking in search for food, or verbal or gestural requests for food before seeing food or a laid table. Consumption of the first meal was delayed by a mean of 2 (range $0-48$ ) hours. At first arousal of request, mothers memorized the manifestations, measured the infant's blood glucose using a device, and then administered the meal. Energy-dense foods, containing more than $60 \mathrm{kcal} / 100 \mathrm{~g}$, were allowed in limited and increasing amounts at meal requests (meal times or snack times) after consumption of fruit or vegetables. The suggested amounts were $150 \mathrm{~g}$ of vegetables before lunch and dinner and $200 \mathrm{~g}$ of fruit before breakfast. The energy-dense content was calibrated to a further request arousal before the planned subsequent meal time. After 3-14 days of training, mothers became aware of their infants' current blood glucose status before meals by their behavior. ${ }^{1-3}$ The initial request was maintained premeal, with adjusting of meal size, composition, and/or timing of intake. After a few days of trial and error, and sometimes irregular meal times, the mothers were able to arrange their infant's intake so that the initial request appeared before the usual three meal times per day, with an average error of 30 minutes in $90 \%$ of instances ("request recognition" or initial request meal pattern). ${ }^{1-3}$

Both the control $(n=73)$ and trained $(n=70)$ mother-infant pairs were encouraged to increase their physical exercise by outdoor activity. In both groups, the protocol included exclusion of organic (celiac) disease, reassurance about the self-limiting nature of diarrhea, and maintenance of scheduled meals following international recommendations on energy intake.

\section{Design}

The protocol included two visits with diary reporting, measurements, and assessments. An open interval of 1-8 months enabled 143 mother-infant pairs to complete the protocol at recruitment (before training) and at the end of the investigation. The total investigation took $4.9 \pm 2.1$ months in controls and $4.2 \pm 2.3$ months in the trained mother-child pairs. No preprandial blood glucose measurements were made in the 73 control infants, with validated evaluation of initial request and estimation of blood glucose undertaken only in the trained mother-infant pairs. Personal habits regarding maintenance of blood glucose may be personal and idiosyncratic. ${ }^{26} \mathrm{We}$ calculated the mean confidence interval at recruitment $(0.95 \%)$ for the investigative question in all 70 trained infants, and stratified them into groups containing components without significant differences in mean blood glucose.

Some infants who had low mean blood glucose at recruitment could fail any response to "request recognition", because this meal pattern lowered mean blood glucose to the point of imminent subjective insufficiency. ${ }^{1-3,25,26}$ We decided to find the most significant cutoff point on the basis of individual response in mean blood glucose, either significant or not related to training. After finding the cutoff, we performed clinical measurements and assessments in infants with low mean blood glucose separately from those with high mean blood glucose at recruitment and at the end of investigation at 4-5 months.

\section{Measurements}

Mothers measured whole capillary blood glucose in their infants using a portable glucometer (Glucocard Memory, Menarini Diagnostics, Florence, Italy) up to 15 minutes before each meal. The accuracy of these measurements was validated by periodic measurements using the hospital autoanalyzer. Measurement of blood glucose was avoided for up to one hour after consuming even a few grams of food, after changes in ambient temperature, after physical activity such as walking or cycling, and 
while under psychological stress or being feverish, because blood glucose in these circumstances is higher for one hour after cessation of transient metabolic derangement. ${ }^{13,25}$ Sevenday home diaries were used to record blood glucose measurements before the three main meal times, energy and vegetable intake, hours in bed, hours of physical and outdoor activities (weekly mean and standard deviation), and presence or absence of preprandial requesting of food. The mothers compiled the diaries before training and at the end of the study. More details on validation of the measurements used in this study have been reported elsewhere. ${ }^{1-3,13,25,26}$

\section{Blood glucose estimation}

At the end of the investigation, the infants were returned to the laboratory where their mothers stated whether they were hungry or not, and estimated their blood glucose shortly before blood sampling and before breakfast. Blood was sampled in duplicate, centrifuged immediately, and analyzed using an autoanalyzer. The infants were then allowed to eat food brought from home or from the hospital cafeteria under the observation of an investigator.

\section{Additional assessments}

Additional analyses were performed for energy balance, well being, nutrition, and cardiovascular status. Energy balance during the 4-5-month investigation was assessed by changes in arm and leg skin-fold thickness, changes in body weight, and assessment of reported energy and vegetable intake. Structured interviews ascertained the number of days on which diarrhea, vomiting, and consumption of paracetamol and antibiotic agents had occurred during the previous 3 months. Hours of daily physical activity and time spent in bed reported in the 7-day diary were also assessed, because an increase in the former and a small decrease in the latter suggests improvement in well being. ${ }^{13}$ Nutrition was assessed by monitoring hemoglobin, mean cellular volume, transferrin saturation, plasma ferritin, zinc, folate, and vitamin B12 levels. ${ }^{1-3}$ Cardiovascular status was assessed by plasma low-density lipoprotein cholesterol/high-density lipoprotein cholesterol ratio, triglycerides, and high-density lipoprotein cholesterol.

\section{Statistical analysis}

In a previous study, we found a difference in mean blood glucose of $6.2 \pm 6.5 \mathrm{mg} / \mathrm{dL}$ between intervention and control groups. ${ }^{13}$ Based on these figures, our sample size calculations suggested that we needed a minimum of 30 mother-infant pairs in each comparison group to detect a similar difference between index means, with a power of $95 \%$ and a unilateral alpha of 0.05 . Values are expressed as the mean \pm standard deviation. Twenty-one diary blood glucose measurements had a normal distribution around the mean. A confidence interval was calculated to include $95 \%$ of measurements. ${ }^{27}$ We stratified 70 infants by mean blood glucose level and searched for a cutoff point at recruitment between the motherinfant pairs who responded significantly to "request recognition" according to mean blood glucose level and those who did not respond, as we did with adults. ${ }^{13}$ The statistical significance of differences and correlations was set at $P<0.05$. Yates' test and the two-tailed Student's $t$-test on paired or unpaired samples were used to analyze for statistically significant differences, and the two-tailed Student's $t$-test was used for correlations. Significance was set at $P<0.05$ for single measurements. ${ }^{27}$ Our investigations of well being, nutrition, and cardiovascular risk comprised 3-7 tests each. Significance was set at $P<0.01$ for the outcome of a single measurement in these investigations. The Bonferroni correction was applied when required for evaluation of results of multiple comparisons. ${ }^{27,28}$ In multiple analyses, the " $<$ " symbol indicates the least significant $P$ value. We copied the diaries into a special software format that provided mean blood glucose, mean daily energy, vegetable and fiber intake, mean time per day spent outdoors, and mean sleep duration. We put the data into Microsoft Excel (Microsoft Corporation, Redmond, WA) and SAS 8 (SAS Institute Inc, Cary, NC) for statistical analysis and presentation of results.

\section{Results}

\section{Demographic and clinical data}

At recruitment, parental education level, along with mean age, body weight, body mass index, height, skin-fold thickness, arm and leg circumferences, and blood values for the infants did not differ significantly between the control and trained groups and between low and high blood glucose subgroups in both trained and control groups (Tables 1 and 2). The results reported refer to the 143 mother-infant pairs (63 females and 80 males) who participated in the investigation (70 trained pairs versus 73 controls).

\section{Blood glucose estimation}

Mothers came back to the hospital at the end of the study. In the laboratory before blood sampling, each mother stated whether her infant was hungry or not hungry, and estimated blood glucose shortly before blood sampling and before breakfast. Fifty-four hungry infants in the trained group had a significantly lower blood glucose $(74.6 \pm 7.7 \mathrm{mg} / \mathrm{dL})$ than 16 not hungry infants $(96.3 \pm 10.5 \mathrm{mg} / \mathrm{dL} ; P=0.001$, Table 3$)$. Trained mothers of 
Table 2 Effects of training on metabolic and energy intake parameters

\begin{tabular}{|c|c|c|c|c|}
\hline & \multicolumn{2}{|l|}{ Control } & \multicolumn{2}{|l|}{ Trained } \\
\hline & Recruitment & After 5 months & Recruitment & After 5 months \\
\hline Mean premeal BG $(\mathrm{mg} / \mathrm{dL})$ & ND & ND & $86.9 \pm 9.4$ & $76.4 \pm 6.7^{\mathrm{b} * * * *}$ \\
\hline BG diary SD (mg/dL)' & ND & ND & $14.7 \pm 5.5$ & $10.7 \pm 4.8^{\mathrm{b} * * *}$ \\
\hline Energy intake (kcal/day) & $968 \pm 173$ & || $48 \pm 3 \mid 4$ & $946 \pm 230$ & $749 \pm 187^{2 * * *, b * * * *}$ \\
\hline Meals per day ${ }^{2}$ & $4.40 \pm 0.75$ & $4.22 \pm 0.64^{\mathrm{b} * *}$ & $4.39 \pm 0.61$ & $3.92 \pm 0.67^{a} * *, b * *$ \\
\hline Vegetable intake (g/day) & $31 \pm 34$ & $44 \pm\left. 7\right|^{b *}$ & $65 \pm 49$ & $344 \pm 133^{\mathrm{a} * * *, \mathrm{~b} * * * *}$ \\
\hline Fruit intake (g/day) & $39 \pm 42$ & $52 \pm 52^{\mathrm{b} * *}$ & $100 \pm 64$ & $214 \pm 107 \approx * * *, b * * * *$ \\
\hline Diarrhea (days/90 days) & $38.8 \pm 3.0$ & $15.6 \pm 22.7^{\mathrm{b} * * *}$ & $47.0 \pm 31.6$ & $3.8 \pm 9.72 * * *, b * * *$ \\
\hline
\end{tabular}

Notes: 'Diary SD refers to the mean of the mean BG SD of 21 measurements reported in a 7-day diary; ${ }^{2}$ meal was an event of higher intake than $20 \mathrm{kcal}$. Values are expressed as mean $\pm S D$. $* P<0.05$; $* * P<0.01$; $* * * P<0.00$ I, Student's $t$-test, pre/post difference versus arespective control group, decrease versus bvalue of the same group at recruitment.

Abbreviations: BG, blood glucose; SD, standard deviation; ND, not done.

hungry infants were able to estimate blood glucose $(77.4 \pm 3.6 \mathrm{mg} / \mathrm{dL}$; estimation error $5.8 \pm 4.5 \mathrm{mg} / \mathrm{dL}$, absolute difference from measured blood glucose) more accurately than the mothers of not hungry infants (estimated blood glucose $88.7 \pm 5.9 \mathrm{mg} / \mathrm{dL}$; estimation error $10.9 \pm 7.5 \mathrm{mg} / \mathrm{dL} ; P=0.0001$ ), indicating that mothers can recognize a food request as a manifestation of a constant (low) blood glucose level in their infants, ie, corresponding to a physiological identifiable condition.

\section{Stratification of trained infants by preprandial blood glucose}

At recruitment, mean blood glucose ranged from 65.0 to $112.3 \mathrm{mg} / \mathrm{dL}$ in the 70 infants, all of whom had diary recordings for blood glucose. The mean confidence interval (95\%) of diary measurements around mean blood glucose was $\pm 6.29 \mathrm{mg} / \mathrm{dL}$. The 70 trained infants were stratified into four groups according to increasing mean blood glucose at recruitment. Each of the four stratification levels included infants who showed no difference in mean blood glucose ( $P>0.05$, Student's $t$-test) from others in the same stratum, but excluded infants who showed significant differences. The four strata comprised four, 42, 25, and one infant in a sequence of increasing mean blood glucose.

\section{Subgroups according to response to "request recognition"}

Figure 1 shows the increasing mean blood glucose sequence in 70 trained infants and their response to "request recognition" training. A significant decrease in mean blood glucose after training occurred mainly in infants with high mean blood glucose at recruitment, whereas mean blood glucose remained relatively constant in infants with low blood glucose at recruitment. The cutoff value of mean blood glucose that most significantly divided these two subgroups was identified as being $81.2 \mathrm{mg} / \mathrm{dL}$. Figure 1 shows mean blood glucose differences, ie, end investigation minus recruitment values as a function of the mean blood glucose level at recruitment. Twenty-one infants with low blood glucose below this cutoff point formed the low blood glucose subgroup, comprising two infants who had a significantly decreased daily energy intake and mean blood glucose level. Forty-nine infants above this cutoff level formed the high mean blood glucose subgroup, comprising 36 infants who had a significantly decreased daily energy intake and mean blood glucose (Chi-square, $P<0.0001$, Table 4). At recruitment (before training), the low blood glucose and high blood glucose subgroups showed no significant differences, except for mean blood glucose levels.

\section{Effects of "request recognition" in the trained group}

Body weight increased normally in the trained infants, without any differences from control infants (Table 1). Skin-fold thickness remained at about the 20th percentile of the US healthy reference value, similar to the control infants. Vegetable and fruit intake increased, and energy intake and days with diarrhea decreased significantly more in trained

Table 3 Estimation of blood glucose by mothers on food request from their infants in hospital just before blood sampling

\begin{tabular}{|c|c|c|c|c|c|c|c|}
\hline \multicolumn{4}{|c|}{54 infants requested food before sampling } & \multicolumn{4}{|c|}{16 infants did not request food } \\
\hline Estimation' & Measurement & Difference & Estimation error ${ }^{3}$ & Estimation & Measurement & Difference & Estimation error \\
\hline $77.4 \pm 3.6^{2}$ & $74.6 \pm 7.7$ & $-3.0 \pm 6.7$ & $5.8 \pm 4.5^{2}$ & $88.7 \pm 5.9$ & $96.3 \pm 10.5$ & $-7.6 \pm 11.1$ & $10.9 \pm 7.5^{2}$ \\
\hline
\end{tabular}

Notes: 'Mothers stated whether the infant had either requested food or not, and estimated glycemia just before blood sampling; ${ }^{2} \mathrm{mean} \pm$ standard deviation, mg/dL; ${ }^{3}$ absolute value of the difference between estimated and measured blood glucose in $\mathrm{mg} / \mathrm{dL}$. $P<0.01$ versus infants requesting food. 


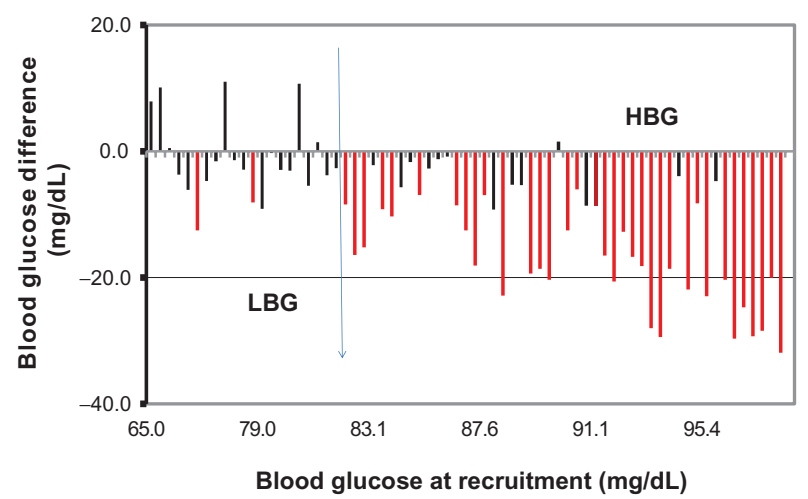

Figure I Difference in mean blood glucose after training versus value from 7-day diary at recruitment for each trained subject.

Notes: Column height shows 5-month mean blood glucose minus recruitment value in each trained subject. Significant decreases in red and nonsignificant changes in black. Mean blood glucose reported in sequentially increasing order at recruitment, not in linear correlation with segment length on the x-axis scale. The vertical division indicates the most significant division between subjects who showed no mean blood glucose decrease after training (LBG group, $\mathrm{n}=21$ subjects) and those who showed significant decrease of mean blood glucose (HBG group, $\mathrm{n}=49$ subjects; $\chi^{2}$ analysis: $P=0.0000 \mathrm{I}$ ). This threshold blood glucose at recruitment (demarcation point) is $81.2 \mathrm{mg} / \mathrm{dL}(4.5 \mathrm{mmol} / \mathrm{L})$.

Abbreviations: HBG, high blood glucose; LBG, low blood glucose.

than in control infants, without any differences between infants with low or high blood glucose (Table 2).

\section{Effects of "request recognition" in subgroups}

In infants with low blood glucose (mean $<81.2 \mathrm{mg} / \mathrm{dL}$, $\mathrm{n}=21,30.0 \%$, Table 4 ) mean blood glucose levels remained constant after training (pre $76.4 \pm 4.5 \mathrm{mg} / \mathrm{dL}$, post $75.2 \pm 6.6 \mathrm{mg} / \mathrm{dL}$, Table 4), whereas in infants with high blood glucose ( $\geq 81.2 \mathrm{mg} / \mathrm{dL}, \mathrm{n}=49,70.0 \%$, Table 4$)$ mean blood glucose decreased significantly after training (pre $91.3 \pm 7.2 \mathrm{mg} / \mathrm{dL}$, post $76.9 \pm 6.7 \mathrm{mg} / \mathrm{dL}, P<0.0001$, Table 4 ). The standard deviation of the diary recording of blood glucose decreased significantly in both the low and high blood glucose subgroups, without any differences. Days of consumption of paracetamol and/or antibiotics in the low blood glucose group decreased significantly after training compared with the control infants (Table 4). There were no significant differences in well being, nutrition, and cardiovascular risk between the trained and control infants for the low and high blood glucose subgroups.

\section{Discussion}

We did not find any differences on blood testing or anthropometric measures in our infants with diarrhea either before or after recovery or between those reared with scheduled or requested food. However, we found a correlation between requested meals and a lower number of diarrhea relapses, lower energy intake, lower mean blood glucose, and small standard deviation of blood glucose. These values and persistence of the intestinal disorder contradicted the null hypothesis regarding scheduled or requested meals. All three factors are causally related. ${ }^{13-21}$ Energy intake and blood glucose values were significantly different, both being lower in infants requesting meals. Low mean blood glucose is associated with insulin sensitivity, regression of proinflammatory states, and functional bowel disorders in adults trained to recognize hunger. ${ }^{13}$

Table 4 Different changes in low and high blood glucose subjects

\begin{tabular}{|c|c|c|c|c|c|c|}
\hline & \multirow{2}{*}{\multicolumn{2}{|c|}{ Control }} & \multicolumn{2}{|c|}{ Low blood glucose } & \multicolumn{2}{|c|}{ High blood glucose } \\
\hline & & & LBG trained & & HBG trained & \\
\hline & Recruitment & After 5 months & Recruitment & After 5 months & Recruitment & After 5 months \\
\hline Age (months)' & $16.7 \pm 2.3$ & $22.5 \pm 6.6$ & $17.2 \pm 6.6$ & $21.1 \pm 6.3$ & $18.4 \pm 7.7$ & $22.7 \pm 8.2$ \\
\hline Weight (kg) & $10.5 \pm 1.7$ & $11.0 \pm 1.8$ & $10.5 \pm 2.5$ & $11.4 \pm 2.4^{\mathrm{a} * *}$ & $10.3 \pm 2.1$ & $1 I . I \pm 2.1$ \\
\hline Height $(\mathrm{cm})$ & $78.5 \pm 6.8$ & $83.2 \pm 6.2$ & $80.5 \pm 8.1$ & $84.3 \pm 7.2$ & $80.5 \pm 8.1$ & $84.0 \pm 7.3$ \\
\hline Arm skin-fold thickness (mm) & $6.7 \pm 1.5$ & $7.1 \pm 1.3$ & $7.5 \pm 1.6$ & $7.5 \pm 1.8$ & $6.9 \pm 1.5$ & $6.9 \pm 1.5$ \\
\hline Leg skin-fold thickness (mm) & $10.5 \pm 3.0$ & $11.4 \pm 3.4$ & $11.9 \pm 4.0$ & $12.3 \pm 3.8$ & $11.0 \pm 2.4$ & $10.9 \pm 2.4$ \\
\hline Energy intake (kcal/day) & $968 \pm 173$ & $1148 \pm 314$ & $979 \pm 261$ & $823 \pm 173^{a * * *, b * *}$ & $932 \pm 217$ & $717 \pm 185^{a * * *, b * * *}$ \\
\hline Mean premeal BG $(\mathrm{mg} / \mathrm{dL})$ & ND & ND & $76.4 \pm 4.5$ & $75.2 \pm 6.6$ & $91.3 \pm 7.2$ & $76.9 \pm 6.7^{\mathrm{b} * * *}$ \\
\hline BG diary SD (mg/dL)' & ND & ND & $14.7 \pm 4.7$ & $10.8 \pm 5.3^{\mathrm{b} * *}$ & $14.7 \pm 5.9$ & $10.7 \pm 4.6^{\mathrm{b} * * * *}$ \\
\hline $\begin{array}{l}\text { Outdoor and gym hours } \\
\text { (hours/day) }\end{array}$ & $3.1 \pm 2.6$ & $2.9 \pm 2.4$ & $2.4 \pm 1.7$ & $3.5 \pm 2.3^{\text {a* }}$ & $2.5 \pm 1.8$ & $3.3 \pm 1.9^{\text {a* }}$ \\
\hline Drug intake (days/30 days) & $8.6 \pm 18.5$ & $6.1 \pm 18.8^{b *}$ & $20.1 \pm 23.9$ & $0.7 \pm 2.6^{\mathrm{a} * * *, b * * *}$ & $10.6 \pm 18.8$ & $2.4 \pm 7.7^{\text {b*** }}$ \\
\hline Diarrhea (days/90 days) & $38.8 \pm 3.0$ & $15.6 \pm 22.7^{b * * * *}$ & $45.5 \pm 30.7$ & $4.3 \pm 8.0^{a * *, b * * *}$ & $47.6 \pm 32.3$ & $3.8 \pm 10.5$ a***,b*** \\
\hline
\end{tabular}

Notes: Low blood glucose (LBG): $<81.2 \mathrm{mg} / \mathrm{dL}$. High blood glucose (HBG): $>81.2 \mathrm{mg} / \mathrm{dL}$. 'Diary SD refers to mean BG standard deviations of $2 \mathrm{I}$ measurements reported in a 7-day diary. Drug intake reports number of days with consumption of analgesics and/or antibiotics. Values are expressed as the mean $\pm \mathrm{SD}$. $* P<0.05$; $* * P<0.01$; $* * * P<0.001$, Student's $t$-test, pre/post difference versus arespective control group, versus 'same group at recruitment, or 'trained low blood glucose group at recruitment. Abbreviations: BG, blood glucose; ND, not done; SD, standard deviation. 
Fruit and vegetable intake increased significantly more in the trained group than in the control group, without any difference found between low and high blood glucose infants. An increase in vegetable intake alone produced a decrease in energy intake in adults, but was ineffective for blood glucose and body weight. ${ }^{26}$ We now persist in training an increase in fruit and vegetables up to the amount of $0.5 \mathrm{~kg} /$ day before the age of two years, fruit before breakfast (200 g), and vegetables (150 g) before lunch and dinner. Fruit and vegetables have an ancillary or permissive role in adapting meals to initial request arousal before planned meal times. Fruit and vegetables are useful for a number of reasons. In children, fruit and vegetables verify the initial request, and help intake stop. In overweight adults vegetables can prevent slightly depressed blood glucose levels during training. We consistently promoted outdoor activity to build an adult body with more muscle and bone content than stored fat.

Habits in intake are not merely mental. During fattening, endocrine cells increase, like beta cells in pancreas, or decrease like cells producing glucagon like peptide..$^{29-34}$ One review has summarized the data for the effect of early imprinting on subsequent energy intake behavior. ${ }^{31} \mathrm{~A}$ total of 300,000 infants experienced the Dutch famine during 1945-1946 in the last trimester before birth or during the first 5 months after birth. At the age of 19 years, they showed a $40 \%$ lower prevalence of overweight. ${ }^{31}$ Formula feeding or overweight in infancy may increase the risk of subsequent obesity by greater leptin concentrations relative to fat mass in 197 adolescents aged 13-16 years who were born preterm. ${ }^{32}$ Early measures at $9-10$ years of waist circumference and triglyceride levels were significant predictors for development of the metabolic syndrome at the age of $18-19$ years. ${ }^{33}$ Early age of rebound adiposity was associated with a markedly increased risk of type 2 diabetes in adulthood. ${ }^{34}$

We investigated the maintenance and long-term effects of training after 4 and 10 years of follow-up. ${ }^{35,36}$ In comparison with 32 randomized controls, 82 trained children in the second year of life maintained a significantly lower $(15 \%-30 \%)$ energy intake for 4 years. ${ }^{35}$ During this period of time, we did not find any differences in growth rate, skin-fold thickness, behavior between meals, intellectual and physical milestones, or blood parameters. ${ }^{35}$ At a mean age of 10 years, we found that mean blood glucose was $90.0 \pm 5.4 \mathrm{mg} / \mathrm{dL}$ in four controls and $82.8 \pm 10.8 \mathrm{mg} / \mathrm{dL}$ in 19 trained children $(P<0.05)$; weight for height increased by $10.3 \% \pm 13.7 \%$ in 43 controls and by $3.1 \% \pm 12.5 \%$ in 43 trained children $(P<0.05)$. At end of the investigation, weight for height and daily energy intake were significantly higher, and vegetable and fruit intake was lower in controls than in trained children. ${ }^{36}$ Development of Helicobacter pylori infection was prevented in trained children. ${ }^{36}$ On the other hand, we found maintenance of a low mean preprandial blood glucose pattern in a minority of all subgroups of infants, children, adults of normal weight, and overweight adults that we investigated before training.

The representativeness of the infants investigated in this study with regard to healthy infants is doubtful. Infants with diarrhea have thinner arm and leg skin-folds and lower weight for height than reference children in the second year of life. ${ }^{2,3,35,37}$ After 2-3 years of age, they have no more diarrhea, ${ }^{35,36}$ but maintain significantly lower basal insulin levels than do normal children. ${ }^{35}$ They reach the mean reference value for weight, but not for skin-folds, at 6 years of age, suggesting that they have thinner fat mass than children of normal weight. ${ }^{35}$ Low subcutaneous tissue and poor insulin production may increase the prevalence of selfrecovering events of insulin resistance and associated bouts of diarrhea. The low weight for height prompts mothers to increase their infant's energy intake. ${ }^{35} \mathrm{~A}$ positive imbalance between intake and expenditure decreased absorption in animal and human experiments. ${ }^{20,21,45,46}$ During positive imbalance, intestinal microflora grows and produces an increase in inflammatory infiltrate in the small intestine and reversible functional derangements. ${ }^{1-21,38-42}$ In experimental animals, we have described an increase of inflammatory cells in the mucosa after administration of broth culture containing Escherichia coli. ${ }^{43}$ This bacterium was not a pathogen, although it elicited an immune response, and was an immunogenic component of intestinal microflora. We showed growth of microflora in biopsies of children during absorption, and a decrease in bacteria numbers after the last meal. ${ }^{44}$ Subjects with irritable bowel syndrome (in infancy, chronic nonspecific diarrhea) actually show an increase in mucosal inflammatory cells. ${ }^{38-42}$ In our investigations, diarrhea relapses arose from an imbalance between energy intake and expenditure in subjects with poor insulin and fattening responses. ${ }^{2,3,13,25,35,36,44-46} \mathrm{~A}$ decrease in energy intake at cessation of scheduled meals stopped diarrhea relapses in infants ${ }^{1-3}$ as well as in adults. ${ }^{13}$ After the age of 2 years, the immune response in the mucosa becomes similar to that in adults, and a proinflammatory state is generated 
by maintenance of scheduled meals and overgrowth of microflora. ${ }^{14-21,38-42}$

\section{Conclusion}

Infants with relapsing diarrhea are more sensitive than other infants to a positive energy imbalance, eg, during scheduled meals, because they have lower production of insulin and thinner skin-folds. The choice between scheduled and requested meals may be a historical or fashion issue. In the first days of life, these two feeding options are equivalent, and are dictated by familial and medical customs, current local fashion, convenience, and also by a null hypothesis, which is wrong. Currently, a "crowd effect" by the general intake trend may nullify any intake education at an early age like in this report. Given the fact that part of the population maintains low preprandial blood glucose by free choice, given the demonstrated maintenance of requested meals up to 12 years of age, the equivalence of early instructions for new mothers, the habitual, persistent nature of mean blood glucose due to associated organic changes, and emphasizing better health in children and adults who maintain preprandial low blood glucose, a change in instructions on rearing seems obvious and mandatory from the neonatal days. This change might help many people to maintain low blood glucose levels.

\section{Acknowledgments}

The authors wish to thank Laura Chiesi and Stefania Bini for the dietary analysis, Massimiliano Sifone for help with the statistical analysis, and Stella Sagaria for technical support. David Lowell-Smith, Stephen Buetow, Tim Kenealy, Chris Harshaw, Simon Thornton, Kent Berridge, James Gibbs, Charlotte Erlanson-Albertsson, and Michael Hermanussen are also thanked for their helpful insights on earlier drafts of this research. This research was supported by the Italian Ministry of University, Research, Science and Technology grants for the years 1998-2002 and ONLUS Nutrizione e Prevenzione, Firenze, for the years 2003-2008.

\section{Disclosure}

The authors declare that they have no competing interests in this work.

\section{References}

1. Ciampolini M, Fognani G, van Weeren M, Borselli L. Attention to metabolic hunger for a steadier (SD decrease to 60\%), slightly lower glycemia $(10 \%)$, and body weight recovery in malnutrited infants. Annual Meeting of the Society for the Study of Ingestive Behavior, 2000. Dublin, Ireland, July 25-29, 2000. (Abstract). Appetite. 2000;35:282.

2. Ciampolini M, Conti A, Bernardini S, et al. Internal stimuli controlled lower calorie intake: effects after eight months in toddler's diarrhoea. Ital J Gastroenterol. 1987;19:201-204.
3. Ciampolini M, Vicarelli D, Seminara S. Normal energy intake range in children with chronic non-specific diarrhea. Association of relapses with the higher level. J Pediatr Gastroenterol Nutr. 1990;11: 342-350.

4. Stam R, Akkermans LM, Wiegant VM. Trauma and the gut: interactions between stressful experience and intestinal function. Gut. 1997;40: 704-709.

5. Carmen A, Guilarte M, Vicario M, et al. Maladaptive intestinal epithelial responses to life stress may predispose healthy women to gut mucosal inflammation. Gastroenterology. 2008;135:163-172.

6. Ferrier L, Mazelin L, Cenac N. Stress-induced disruption of colonic epithelial barrier: role of interferon- and myosin light chain kinase in mice. Gastroenterology. 2003;125:795-804.

7. de Graaf C, Blom WAM, Smeets PAM, Stafleu A, Hendriks HFJ. Biomarkers of satiation and satiety. Am J Clin Nutr. 2004;79:946-961.

8. Gavin JR. Pathophysiologic mechanisms of postprandial hyperglycemia. Am J Cardiol. 2001;88:S4-S8.

9. Elliott SS, Keim NL, Stern JS, Teff K, Havel PJ. Fructose, weight gain, and the insulin resistance syndrome. Am J Clin Nutr. 2002;76:911-922.

10. Westerterp KR. Diet induced thermogenesis. Nutr Metab (Lond). 2004;1:5.

11. Van Wymelbeke V, Himaya A, Louis-Sylvestre J, Fantino M. Influence of medium-chain and long-chain triacylglycerols on the control of food intake in men. Am J Clin Nutr. 1998;68:226-234.

12. Summers LKM, Barnes SC, Fielding BA, et al. Uptake of individual fatty acids into adipose tissue in relation to their presence in the diet. Am J Clin Nutr. 2000;71:1470-1477.

13. Ciampolini M, Sifone M. Differences in maintenance of mean blood glucose (BG) and their association with response to "recognizing hunger". Int J Gen Med. 2011;4:403-412.

14. Festa A, D'Agostino R Jr, Howard G, Mykkänen L, Russell PT, Haffner SM. Chronic subclinical inflammation as part of the insulin resistance syndrome: the Insulin Resistance Atherosclerosis Study (IRAS). Circulation. 2000;102:42-47.

15. Reaven GM. The metabolic syndrome: is this diagnosis necessary? Am J Clin Nutr. 2006;83:1237-1247.

16. Smith CW. Diet and leukocytes. Am J Clin Nutr. 2007;86:1257-1258.

17. Bigorgne AE, Bouchet-Delbos L, Naveau S, et al. Obesity-induced lymphocyte hyperresponsiveness to chemokines: a new mechanism of fatty liver inflammation in obese mice. Gastroenterology. 2008;134: 1459-1469.

18. Cani PD, Amar J, Iglesias MA, et al. Metabolic endotoxemia initiates obesity and insulin resistance. Diabetes. 2007;56:1761-1767.

19. Stratton IM, Adler AI, Neil HAW, et al; on behalf of the UK Prospective Diabetes Study Group. Association of glycaemia with macrovascular and microvascular complications of type 2 diabetes (UKPDS 35): prospective observational study Br Med J. 2000;321:405-412.

20. Jumpertz R, Le Duc S, Turnbaugh PJ, et al. Energy-balance studies reveal associations between gut microbes, caloric load, and nutrient absorption in humans. Am J Clin Nutr. 2011;94:58-65.

21. Waidmann M, Bechtold O, Frick JS, et al. Bacteroides vulgatus protects against Escherichia coli-induced colitis in gnotobiotic interleukin-2deficient mice. Gastroenterology. 2003;125:162-177.

22. Sumithran P, Prendergast LA, Delbridge E, et al. Long-term persistence of hormonal adaptations to weight loss. N Engl J Med. 2011;365: $1597-1604$

23. Mozaffarian D, Hao T, Rimm EB, Willett WC, Hu FB. Changes in diet and lifestyle and long-term weight gain in women and men. $N$ Engl J Med. 2011;364:2392-2404.

24. Butte NF, Garza C, O'Brian Smith E, Nichols BLV. Human milk intake and growth in exclusively breast-fed infants. J Pediatr. 1984;104: 187-195.

25. Ciampolini M, Bianchi R. Training to estimate blood glucose and to form associations with initial hunger. Nutr Metab (Lond). 2006;3:42.

26. Ciampolini M, Lovell-Smith D, Sifone M. Sustained self-regulation of energy intake. Loss of weight in overweight subjects. Maintenance of weight in normal-weight subjects. Nutr Metab (Lond). 2010;7:4. 
27. Armitage P, Berry G. Statistical Methods in Medical Research. 3rd ed. Oxford, UK: Blackwell; 1994

28. Godfrey K. Comparing the means of several groups. N Engl J Med. 1985;313:1450-1456.

29. Weiss R. Insulin sensitivity and secretion: swaying the pendulum. GH, growth hormone, IGF-I, insulin-like growth factor. $J$ Pediatrics. 2006;148:3-4.

30. Verdich C, Toubro S, Buemann B, Madsen JL, Holst JJ, Astrup A. The role of postprandial releases of insulin and incretin hormones in meal induced satiety. Effect of obesity and weight reduction. Intern J Obesity. 2001;25:1206-1214.

31. Waterland RA, Garza C. Potential mechanisms of metabolic imprinting that lead to chronic disease. Am J Clin Nutr. 1999;69:179-197.

32. Singhal A, Cole TJ, Fewtrell M, Lucas A. Breastmilk feeding and lipoprotein profile in adolescents born preterm: follow-up of a prospective randomised study. Lancet. 2004;363:1571-1578.

33. Dolan LM, Bean J, D'Alessio D, et al. Frequency of abnormal carbohydrate metabolism and diabetes in a population-based screening of adolescents. $J$ Pediatrics. 2005;146:751-758.

34. Eriksson JG. Early growth and coronary heart disease and type 2 diabetes: findings from the Helsinki Birth Cohort Study (HBCS). Am J Clin Nutr. 2011;94:1799S-1802S.

35. Ciampolini M, Bini S, Giommi A, Vicarelli D, Giannellini V. Same growth and different energy intake over four years in children suffering from chronic non-specific diarrhea. Int J Obesity. 1994;18:17-23.

36. Ciampolini M, Borselli L, Giannellini V. Attention to metabolic hunger and its effects on Helicobacter pylori infection. Physiol Behav. 2000; 70:287-296.
37. Frisancho AR. New norms of upper limb fat and muscle areas for assessment of nutritional status. Am J Clin Nutr. 1981;34:2540-2545.

38. Ohman L, Simrén M. Pathogenesis of IBS: role of inflammation, immunity and neuroimmune interactions. Nat Rev Gastroenterol Hepatol. 2010;7:163-173.

39. Törnblom H, Lindberg G, Nyberg B, Veress B. Full-thickness biopsy of jejunum reveals inflammation and enteric neuropathy in irritable bowel syndrome. Gastroenterology. 2002;123:1972-1979.

40. Hecht G. In the beginning was Helicobacter pylori: roles for microbes in other intestinal disorders. Gastroenterology. 2007;132:481-483.

41. Fiocchi C. One commensal bacterial molecule - all we need for health? N Engl J Med. 2005;353:2078-2080.

42. Shanahan F. Irritable bowel syndrome: shifting the focus toward the gut microbiota. Gastroenterology. 2007;133:340-342.

43. Ciampolini M, Marianelli L. Azione dei germi nel tenue. Nota II: E.Coli nel ratto lattante. Studio microbiologico, istologico e biochimico [Bacterial effects on small intestine. II E coli in suckling rats. Microbiology, histology and biochemestry investigations]. Riv Clin Ped. 1969;82:78-84. Italian.

44. Ciampolini M, Bini S, Orsi A. Microflora persistence on duodenojejunal flat or normal mucosa in time after a meal in children. Physiol Behav. 1996;60:1551-1556.

45. Ciampolini M. Influence of environmental temperature on intestinal absorption of xylose in rats in vivo. International Research Communications System (IRCS) Alimentary System; Metabolism and Nutrition; Pediatrics and Perinatal Medicine; Physiology. 1974;2:1545.

46. Ciampolini M. Influence of environmental temperature on xylose absorption in man. IRCS Med Sci. 1976;4:208.
International Journal of General Medicine

\section{Publish your work in this journal}

The International Journal of General Medicine is an international, peer-reviewed open-access journal that focuses on general and internal medicine, pathogenesis, epidemiology, diagnosis, monitoring and treatment protocols. The journal is characterized by the rapid reporting of reviews, original research and clinical studies across all disease

\section{Dovepress}

areas. A key focus is the elucidation of disease processes and management protocols resulting in improved outcomes for the patient. The manuscript management system is completely online and includes a very quick and fair peer-review system. Visit http://www.dovepress. com/testimonials.php to read real quotes from published authors. 